\title{
Early development of the Peruvian rock seabass Paralabrax humeralis (Teleostei: Serranidae): morphological description of the embryonic and yolk-sac larval stages
}

\author{
Masatoshi Futagawa $\left.\right|^{1} \mathbb{C}$, Jessica Pizarro $\left.\right|^{1} \mathbb{C}$, German Bueno $\left.\right|^{1} \mathbb{C}$ \& Juan Pablo Díaz $\left.\right|^{1}$ \\ ${ }^{1}$ Universidad Arturo Prat, Iquique, Chile \\ Corresponding author: Masatoshi Futagawa (mafutaga@unap.cl)
}

\begin{abstract}
Describe the embryonic development of Paralabrax humeralis (Peruvian rock seabass) and the present morphology of its eggs and yolk-sac larvae using the eggs spawned by $P$. humeralis broodstock in captivity. The spawning occurred naturally and spontaneously in early November 2018. The egg is pelagic and round, with a diameter of $0.98 \pm 0.02 \mathrm{~mm}$, an oil globule, and a diameter of $0.2 \pm 0.02 \mathrm{~mm}$. Embryonic development started with meroblastic cleavage, reaching the first cleavage stage at $0.4 \mathrm{~h}$ post-fertilization (HPF), and reached 64 cells at 2.2 HPF. Blastula period, 128 cells to $30 \%$ epiboly, end at $11.3 \mathrm{HPF}$. Gastrula period, $50 \%$ epiboly to $90 \%$ epiboly, end at $19.6 \mathrm{HPF}$. In the organogenesis period, forming Kupffer's vesicle appeared at 22.5 HPF, the separation of the caudal fin from the yolk at $30.3 \mathrm{HPF}$, and the hatching of the first larvae at 47.9 HPF. Water temperature was kept at $17.2 \pm 0.2^{\circ} \mathrm{C}$. The yolk-sac larvae measured $2.22 \pm 0.1 \mathrm{~mm}$ with a pigmentation pattern of pinpoint melanophores, all along with the embryo and xanthophores in the cephalic region, trunk, and caudal region, as well as in the oil globule. The larva takes feeds from three days post-hatchout.
\end{abstract}

Keywords: Peruvian rock seabass; Paralabrax humeralis; Serranidae; early life stages; reproduction

Paralabrax humeralis (Valenciennes, 1828), also known as the Peruvian rock seabass, is a serranid regularly found in the southeast Pacific Ocean (Ojeda et al. 2000). It is a benthopelagic species that lives in rocky-sandy coastal areas among kelp forests (Cisternas \& Sielfeld 2008). P. humeralis is carnivorous with carcinophagus and ichthyophagous tendencies and hermaphrodite with batch spawning strategy (Bórquez et al. 1988, Medina et al. 2004).

In Chile, this species is a target of artisanal and sport fisheries because of the quality of its meat. As a consequence of fishing pressure, its numbers have been declining since the 1980s (SERNAPESCA 2014). $P$. humeralis is considered to be under full exploitation in northern Chile, placing it in a vulnerable but not threatened status (Araya et al. 2015). On a global scale, the International Union for Conservation of Nature (IUCN) has classified it as "data deficient" (SmithVaniz et al. 2015).

Oceans, along with coastal zones, are fragile ecosystems, which are constantly threatened by human activity, particularly the overexploitation of resources. Marine biodiversity can be lost because of resource mismanagement. One strategy for conserving marine biodiversity is to create new technologies for blue economy development and increase food production (Van Hoof et al. 2019). Aquaculture is one example of this kind of technology, so long as it is developed in an economically viable, environmentally sustainable, and socially acceptable way.

$P$. humeralis is one of the native species in northern Chile that shows potential for future aquaculture and repopulation efforts. There is currently little knowledge about the biology of this species, not even basic information on its life cycle (Araya et al. 2015). The main objective of this study was to provide information about the early development of $P$. humeralis, describing the morphology of the embryonic and yolk-sac larval stages. One of the initiatives of the FONDEFCONICYT ID-16I10437 Project is the repopulation of this species. With that aim, in 2018, wild specimens of $P$. humeralis were collected by hook and line in diffe-

Corresponding editor: Alejandra Volpedo 
rent locations along the coast of Iquique in northern Chile $\left(20^{\circ}-20^{\circ} 50^{\prime} \mathrm{S}\right)$. Of those captured, 21 were female breeders with bodyweight between 294-1794 g (825 \pm $408 \mathrm{~g})$ (mean \pm standard deviation), 17 males with a weight between $256-1396 \mathrm{~g}(710 \pm 250 \mathrm{~g})$. These fish were housed in 10,000 L tanks, supplied with unfiltered coastal water, at a temperature of $18.9 \pm 1.0^{\circ} \mathrm{C}$, and natural photoperiod. Fish were fed with choro mussel Choromytilus chorus and Chilean silverside Odontesthes regia meat five days a week, with a diet of $4 \%$ of their body mass. Under these conditions, fish reached gonadal maturity, and spawning began spontaneously on November 9, 2018, at 19:40 h, with the females producing 5,600,100 eggs in 19 batches at a water temperature of $19.2 \pm 1.0^{\circ} \mathrm{C}$. The fertilized eggs were moved to a $60 \mathrm{~L}$ cylindrical-conical tank for incubation and hatching. Approximately 1000 fertilized eggs were collected from one spawning batch and incubated under laboratory conditions to monitor embryonic development, using $1 \mathrm{~L}$ cup with aeration and water circulation at a temperature of $17.2 \pm 0.2^{\circ} \mathrm{C}$ and under natural photoperiod. At different periods, expressed as hours post-fertilization (HPF), eggs samples were collected to register the stage of development in vivo under a light microscope (Carl Zeiss Axilostar puls) coupled to a digital camera (Nikon AW130) or an industrial digital microscope (Hayear HY-2307), after which they were preserved in $5 \%$ formalin. Upon hatching, larvae were sampled and photographed daily until day three post-hatching (DPH). Stages of development were assessed according to Kimmel et al. (1995) with some modifications.

The eggs of $P$. humeralis are spherical and transparent and have a diameter of $0.98 \pm 0.02 \mathrm{~mm}$. They have a smooth chorion and homogenous yolk, surrounded by little perivitelline space. An oil globule of $0.2 \pm 0.02 \mathrm{~mm}$ conferring buoyancy to fertilized eggs is observed within the yolk.

Embryonic development after fertilization starts with the cleavage period. Successive synchronous divisions of the blastodisc located in the animal pole (meroblastic cleavage) give rise to $2,4,8,16,32$, and 64 cells over 2.2 HPF (Fig. 1).

The blastula period, from 128 cells to $30 \%$ epiboly, extends from 2.8 to $11.3 \mathrm{HPF}$. The early blastula (128 cells stage) at $2.8 \mathrm{HPF}$ is observed as a mulberry-like mound of blastomeres located on top of the yolk. At 5.7 HPF (high stage), the blastoderm is formed by a higher number of small-sized blastomeres. At 8.6 HPF (dome stage), the yolk bulges towards the animal pole as epiboly begins. At 11.3 HPF ( $30 \%$ epiboly), the blastoderm is observed as an inverted cup of uniform thickness over the yolk (Fig. 2).

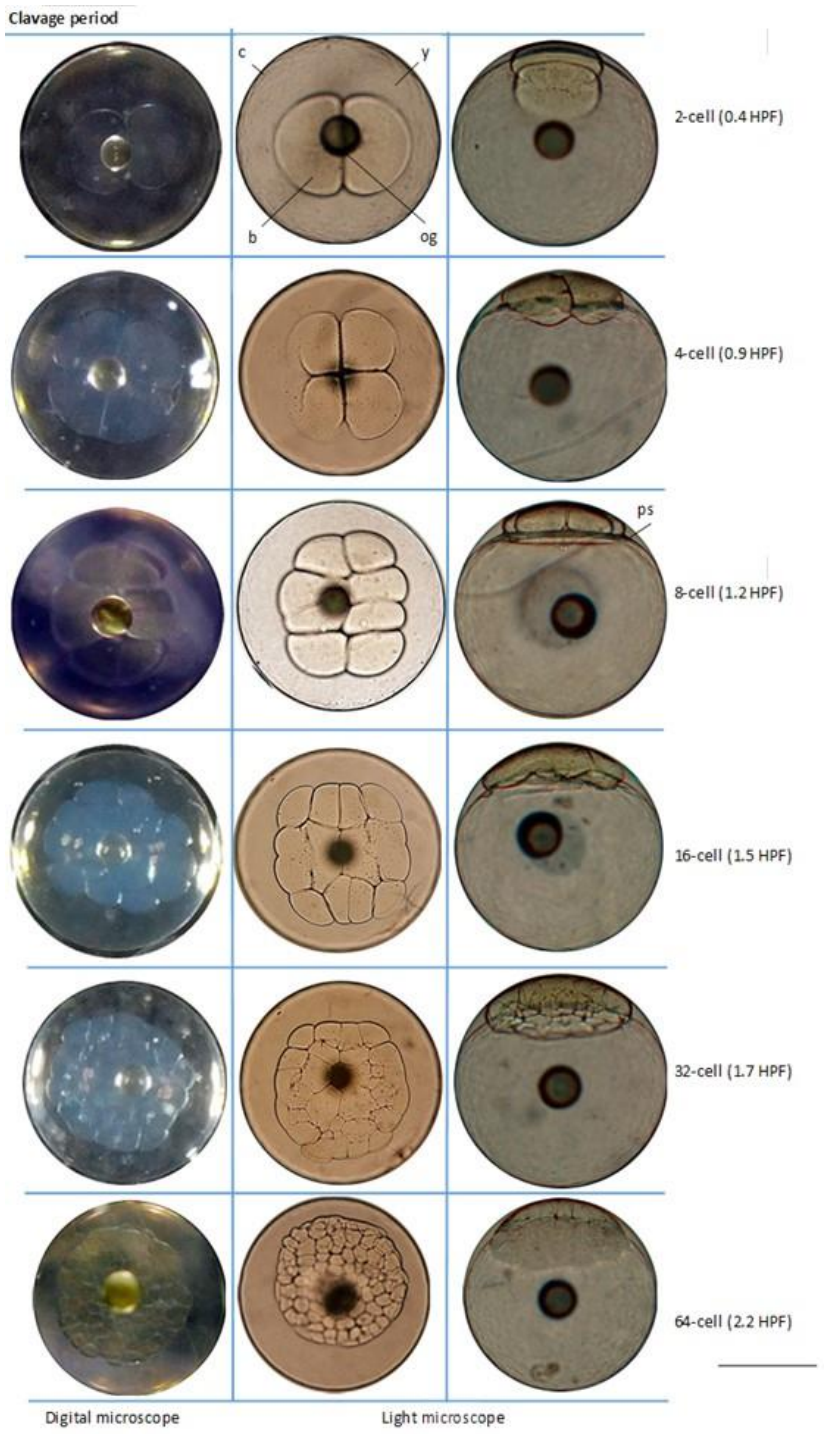

Figure 1. Embryonic development of Paralabrax humeralis in the cleavage period. HPF: hours post-fertilization, b: blastomeres, c: corion, ps: perivitelline space, og: oil globule, y: yolk. Scale bar $=0.5 \mathrm{~mm}$.

During gastrulation, the blastoderm spreads over the yolk covering $50 \%$ of the yolk by $15.5 \mathrm{HPF}, 75 \%$ by 18.7 HPF, and $90 \%$ by $19.6 \mathrm{HPF}$. At the end of gastrulation, a rudimentary cephalic region has been formed. The blastopore closes at 20.3 HPF as the germ ring entirely covers the yolk mass at the vegetable pole. At this point, the outlines of the optic cups are visible, and the tailbud forms at the caudal end of the embryo (Fig. 3).

During organogenesis, primordial organs such as the brain, eyes, notochord, somites, heart, digestive duct, and pharyngeal arches are formed as the cephalocaudal differentiation of the embryo progresses. Kupffer's vesicle forms at $22.5 \mathrm{HPF}$ and pigments 


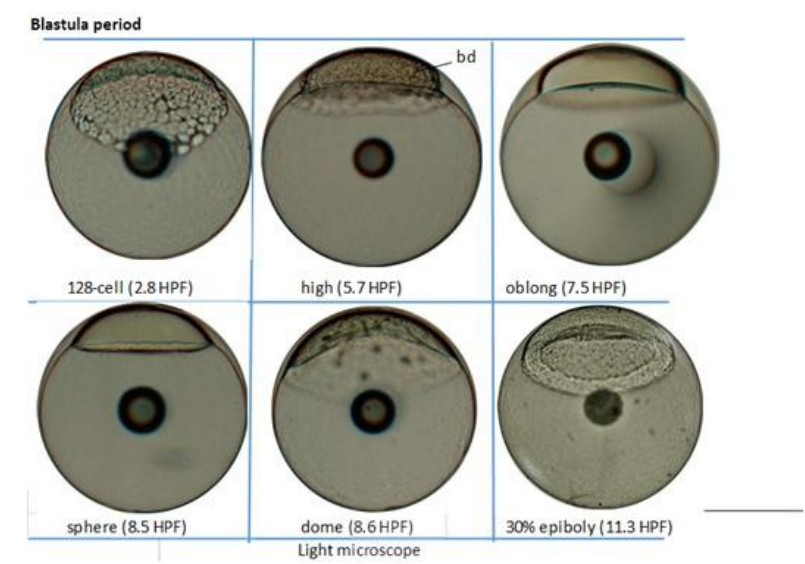

Figure 2. Embryonic development of Paralabrax humeralis in the blastula period. HPF: hours post-fertilization, bd: blastoderm. Bar scale $=0.5 \mathrm{~mm}$.

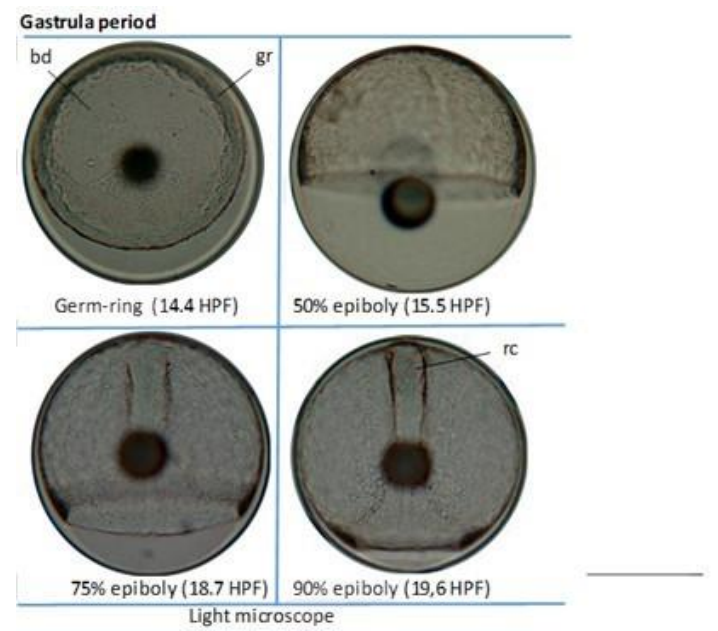

Figure 3. Embryonic development of Paralabrax humeralis in the gastrula period. HPF: hours post-fertilization, bd: blastoderm, gr: germ ring, rc: rudimentary cephalic region. Bar scale $=0.5 \mathrm{~mm}$.

(pinpoint melanophores) appear at 26.5 HPF. At 29.4 $\mathrm{HPF}$, the head region is enlarged, and there are 14 somites throughout the body. The separation of the embryo caudal end from the yolk occurs at $30.3 \mathrm{HPF}$, along with the apparition of pinpoint melanophores in some oil globules. At 32.3 HPF, further development and separation of the caudal end from the yolk mass and a yellow pigmentation (xanthophores) in the body of the embryo and oil in globules are observed. Heartbeats, the first body movements, and the onset of tail end torsion become evident at 38.3 HPF. At 40.7 $\mathrm{HPF}$, the lens is observed within the optic. Before hatching, growth and curvature of the tail region occur. Subsequently, muscular contractions of the embryo tear the chorion, and the larva hatches in a yolk-sac stage at 47.9 HPF (Fig. 4). The chronology of embryonic development is shown (Table 1).

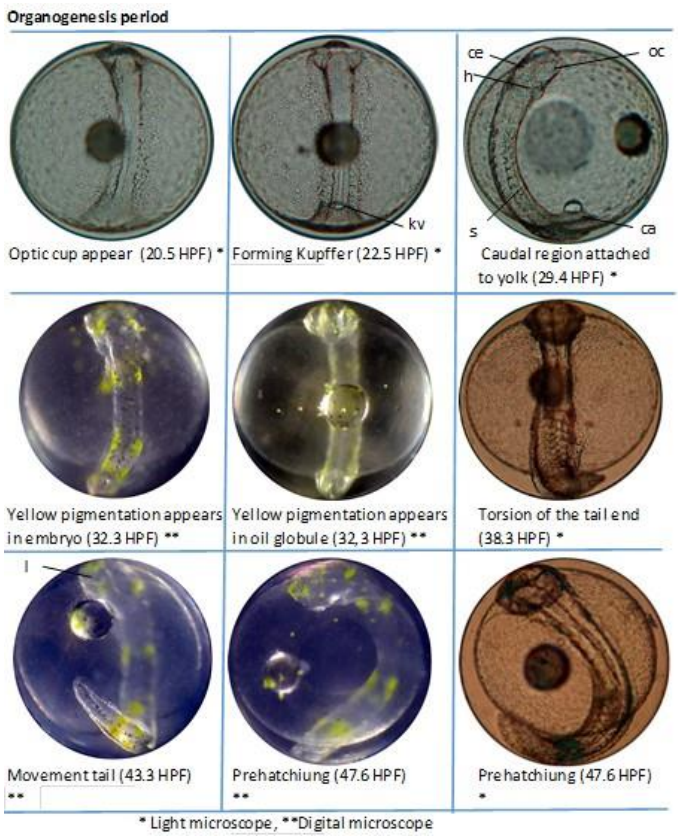

Figure 4. Embryonic development of Paralabrax humeralis in the organogenesis period. HPF: hours postfertilization, ca: caudal region, ce: cephalic region, h: heart, kv: Kupffer's vesicle, 1: lens, oc: optic cups, s: somites. Bar scale $=0.5 \mathrm{~mm}$.

The newly hatched larvae (DPH 0$)$ are $2.22 \pm 0.1$ $\mathrm{mm}$ in length. They exhibit non-pigmented eyes, nonfunctional mouth, embryonic fin-folds, and the oil globule within the yolk-sac. The pigmentation pattern is characterized as pinpoint melanophores along the body and dendriform xanthophores in dorsal and ventral patches at the cephalic region, the trunk, and the caudal region. Black and yellow pigments are also observed anterior to the oil globule. At DPH 1, the body length extends, and the anal opening is observed. The size of the yolk sac is reduced as the yolk is consumed. At DPH 2, the yolk sack is further reduced in size. Brain lobes are well developed, and otoliths become visible within the auditory vesicles. At DPH 3, eye pigmentation is observed. The yolk sack and oil globule have been consumed almost completely. The mouth is opened, and larvae become ready to take exogenous feeding (Fig. 5).

This study describes the early developmental stages of $P$. humeralis, focusing on the morphology of the embryonic and yolk-sac larval stages. It contributes to the current understanding of this species' biology, necessary for aquaculture and possible repopulation initiatives and improved management practices for this coastal fish.

Araya et al. (2015) claimed that the current situation is grave for the majority of coastal fish in northern to 

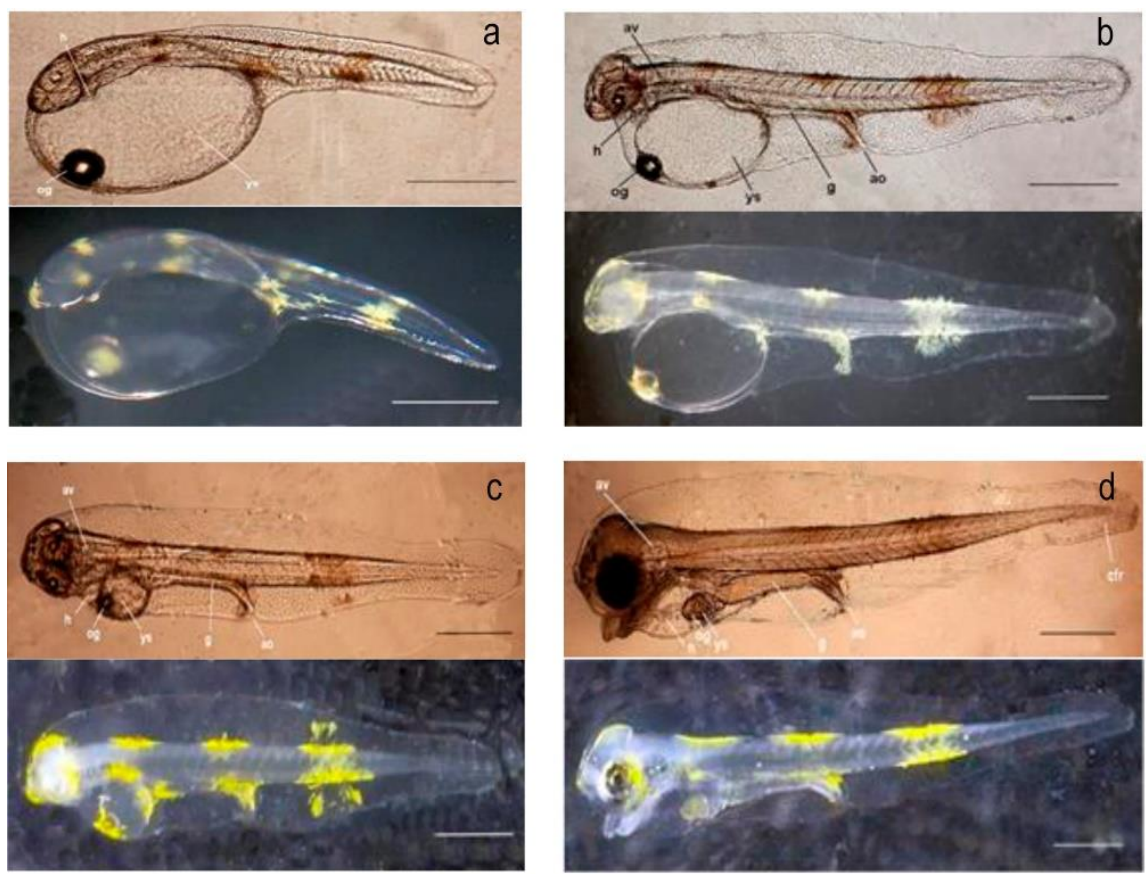

Figure 5. Yolk-sac larval stages of Paralabrax humeralis. Top images: light microscope; bottom images: digital microscope. a) DPH 0: newly hatched larva, b) DPH 1: larva one day post-hatching, c) DPH 2: larva two days post-hatching, d) DPH 3: larva three days post-hatching. HPF: hours post-fertilization, DPH: days post-hatching, ao: anal orifice, av: auditory vesicle, cfr: caudal-fin rays, g: gut, h: heart, og: oil globule, ys: yolk sac. Bar scale $=0.5 \mathrm{~mm}$.

Table 1. Chronology of embryonic development of Paralabrax humeralis.

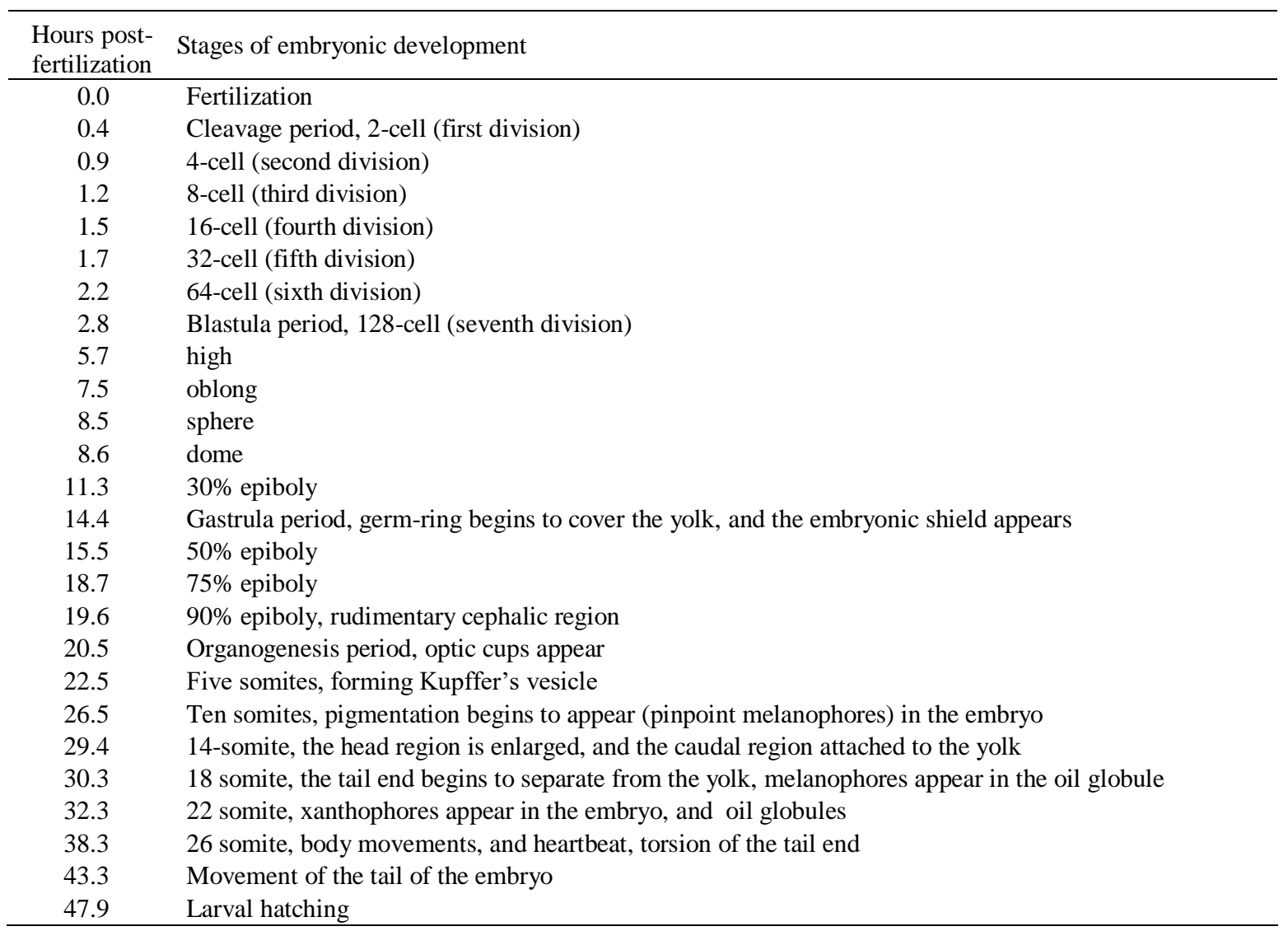


central Chile.There is a lack of information about fish biology so that it is so important to develop studies that define the basic biological aspects of these fish species. This knowledge is the basis for more effective and wellfounded regulation. The management and conservation of any fish population require a well understanding of the entire life cycle, including eggs and larvae (Saka et al. 2006, Strydom 2008).

As for early development, one of the most important variables in hatching success and larval survival is water temperature (Camus \& Koutsikopoulos 1984, Tveiten et al. 2001, Green \& Fisher 2004, Thépot \& Jerry 2015), since it plays an important role in regulating the physiological processes of ontogenesis (Blaxter 1992, Rodríguez-Muñoz et al. 2001). Fish eggs and larvae are very sensitive to fluctuations in water temperature and have only a narrow range of thermic tolerance when compared to adults (Das et al. 2006). In this study, the water temperature was maintained at $17.2 \pm 0.2^{\circ} \mathrm{C}$, simulating the temperature conditions found in the fish's natural environment.

Finally, the knowledge gained from this study can improve fishery management techniques during the reproduction and incubation phases, leading to a more successful culture and repopulation of the rock seabass along the northern coast of Chile.

\section{ACKNOWLEDGMENTS}

The authors would like to thank the FONDEFCONICYT ID-16I10437 project for the support to carry out this study. They would also like to thank the anonymous reviewers for their valuable recommendations.

\section{REFERENCES}

Araya, M., Azócar, C., Claramunt, G., Medina, M., Moreno, P., Oliva, M. \& Vargas, A. 2015. Diagnóstico $\mathrm{y}$ propuesta de manejo sustentable de pesquerías costeras de peces litorales en la XV, I y II Regiones, Iquique, Chile. Proyecto FIP No2013-20, Universidad Arturo Prat, Iquique.

Blaxter, J. 1992. The effect of temperature on larval fishes. Netherlands Journal of Zoology, 42: 336-357. doi: $10.1163 / 156854291 X 00379$

Bórquez, A., Olivares, A. \& Tapia, L. 1988. Estructura gonadal e inversión sexual de la cabrilla común Paralabrax humeralis Valenciennes, 1828 (Pisces: Serranidae). Estudios Oceanológicos, 7: 51-58.

Camus, P. \& Koutsikopoulos, C. 1984. Incubation and embryonic development of gilthead bream, Sparus aurata (L.), at a range of temperatures. Aquaculture, 42: 117-128.

Cisternas, F. \& Sielfeld, W. 2008. Habitat overlap of Paralabrax humeralis (Cuvier \& Valenciennes, 1828), Hemilutjanus macrophthalmos (Tschudi, 1845), and Acanthistius pictus (Tschudi, 1845) (Pisces; Serranidae) in the rocky subtidal south of Iquique, Chile. Latin American Journal of Aquatic Research, 36: 153-158.

Das, T., Pal, A.K., Chakraborty, S.K., Manush, S.M., Dalvi, R.S., Sarma, K. \& Mukherjee, S.C. 2006. Thermal dependence of embryonic development and hatching rate in Labeo rohita (Hamilton, 1822). Aquaculture, 255: 536-541. doi: 10.1016/j.aquaculture.2006.01.013

Green, B.S. \& Fisher, R. 2004. Temperature influences swimming speed, growth, and larval duration in coral reef fish larvae. Journal of Experimental Marine Biology and Ecology, 299: 115-132. doi: 10.1016/j. jembe.2003.09.001

Kimmel, C.B., Ballard, W.W., Kimmel, S.R., Ullmann, B. $\&$ Schilling, T.F. 1995. Stages of embryonic development of the zebrafish. Developmental Dynamics, 203: 253-310.

Medina, M., Araya, M. \& Vega, C. 2004. Alimentación y relaciones tróficas de peces costeros de la zona norte de Chile. Investigaciones Marinas, Valparaíso, 32: 3347.

Ojeda, P., Labra, F. \& Muñoz, A. 2000. Biogeographic patterns of Chilean littoral fishes. Revista Chilena de Historia Natural, 73: 625-651.

Rodríguez-Muñoz, R., Nicieza, A.G. \& Braña, F. 2001. Effects of temperature on developmental performance, survival, and growth of sea lamprey embryos. Journal of Fish Biology, 58: 475-486. doi: 10.1006/jfbi. 2000.1465

Saka, Ş., Firat, K. \& Çoban, D. 2006. Embryonic development of common dentex (Dentex dentex L.) eggs. Turkish Journal of Veterinary and Animal Sciences, 30: 35-40.

Servicio Nacional de Pesca (SERNAPESCA). 2014. Anuario estadístico de pesca y acuicultura, series 1975-2013. Servicio Nacional de Pesca y Acuicultura, Valparaíso.

Smith-Vaniz, B., Robertson, R., Dominici-Arosemena, A., Molina, H., Salas, E., Guzman-Mora, A.G. \& Bearez, P. 2015. Paralabrax humeralis. The IUCN Red List of Threatened Species 2010. International Union for Conservation of Nature and Natural Resources, Gland.

Strydom, N.A. 2008. Utilization of shallow subtidal bays associated with warm temperate rocky shores by the 
late-stage larvae of some inshore fish species, South Africa. African Zoology, 43: 256-269. doi: 10.3377/ 1562-7020-43.2.256

Thépot, V. \& Jerry, D.R. 2015. The effect of temperature on the embryonic development of barramundi, the Australian strain of Lates calcarifer (Bloch) using current hatchery practices. Aquaculture Reports, 2: 132-138. doi: 10.1016/j.aqrep.2015.09.002

Received: August 28, 2020; Accepted: February 9, 2021
Tveiten, H., Solevåg, S.E. \& Johnsen, H.K. 2001. Holding temperature during the breeding season influences final maturation and egg quality in common wolffish. Journal of Fish Biology, 58: 374-385. doi: 10.1006/ jfbi.2000.1448

Van Hoof, L., Gianna, F., Johansen, V., Steenbergen, J., Irigoien, X., Sarah, S. \& Kraus, G. 2019. Food from the ocean; towards a research agenda for sustainable use of our oceans' natural resources. Marine Policy, 105: 44-51. 